\title{
Prioritization of risk events in PPP wind power projects using integrated FMEA and Monte Carlo simulation
}

\author{
Emre Caner Akcay *iD \\ Atılım University, Department of Civil Engineering, Ankara, Turkey
}

\begin{abstract}
The popularity of public private partnership (PPP) projects has grown all over the world, especially in developing countries. The success of PPP projects heavily depends on how effectively risk assessments are performed. Failure Mode and Effects Analysis (FMEA) enables risk assessment by considering the impact, the probability, and the detection rate of risk events. However, it is very difficult to predict a single value for these variables. The objective of this research is to integrate FMEA and Monte Carlo simulation, and to use this model to perform risk assessment and prioritization of risks in PPP projects. The proposed model was applied to a real wind power generation investment located in the Aegean region of Turkey. The top three important risk events are "unfavorable wind speed", "fluctuation in exchange rates", and "interest rate volatility". The model perfumed to the satisfaction of experts. The primary contributions of this research include (1) a method that allows the identification of the risk events in PPP projects; (2) a model that performs risk assessment and prioritization of risk events in PPP projects; (3) an integrated FMEA and Monte Carlo simulation model that performs stochastic risk assessment in PPP projects. Both public agencies and private consortia should benefit from the proposed model.
\end{abstract}

\section{Keywords}

FMEA; Monte Carlo simulation; PPP; Project management; Risk assessment

Received: 15 March 2021; Accepted: 09 June 2021

ISSN: 2630-5771 (online) C 2021 Golden Light Publishing All rights reserved.

\section{Introduction}

Risk is defined as "an uncertain event or condition that, if it occurs, has a positive or negative effect on at least one project objective such as time, cost, span, or quality" [1]. The construction industry carries a higher degree of risks compared to other industries due to its complex and dynamic nature [2]. Risks may have adverse effects on the performance of construction projects [3]. Hence, the success of construction projects heavily depends on how effectively risks are managed [4]. Quite a few projects are undertaken by using Public

\footnotetext{
Corresponding author

Email: caner.akcay@atilim.edu.tr
}

Private Partnerships (PPP) especially in developing countries [5]. PPP is a project delivery system where a public agency and a private consortium make a long-term cooperation agreement to provide public facilities [6]. Compared to typical project delivery systems, in PPP projects, the private consortium provides financing, which makes PPP rather different, which in turn creates different risks that have to be managed effectively to achieve success in the project.

The Society of Risk Analysis [7] defines risk assessment as a systematic process to figure out the nature of the risk and to express the risk with the 
available knowledge. Risk assessment is mainly about quantification of uncertainty and its possible impacts on project success. The risk assessment of construction projects has captured the attention of researchers in the past few decades. Researchers benefit from different risk analysis techniques such as Decision Tree Analysis [8-10], Analytic Network Process (ANP) [11-18], Analytic Hierarchy Process (AHP) [19-22], Risk Matrix [2325], Monte Carlo Simulation [26-31] and fuzzy risk rating [32] in order to estimate risk in a project. There are also some studies that assess risk in PPP projects. For instance, Li and Zou [20] proposed a fuzzy analytical hierarchy process (AHP)-based risk assessment model for PPP projects. Sarvari et al. [23] developed a risk matrix-based model to rank risk in PPP projects in Malaysia. Valipour et al. [14] prioritized important risk factors in freeway PPP projects by using a fuzzy analytic network process (ANP).

Failure Mode and Effects Analysis (FMEA) is an alternative assessment method that determines possible failures, examines the reasons, and assesses the impacts of the failure with the objective of minimizing these impacts [33]. FMEA was initially used to identify potential failures in products, processes and services [34]. In addition, various researchers have assessed project risks by using FMEA [33, 35-38]. For instance, Ahmadi et al. [35] performed risk assessment and prioritization in highway construction projects by using fuzzy FMEA.

FMEA performs risk prioritization by calculating a Risk Priority Number (RPN). This value is calculated by multiplying the impact, the probability of occurrence, and the detection rate of the risk event and reflects the overall risk level of the associated risk event. These three factors that define RPN are rated using a 10-point scale. A risk event that has a higher RPN is more critical compared to other risk events. In contrast to other risk analysis techniques, FMEA enables risk prioritization by considering the detection rate of a risk event. Carbone and Tippett [34] defined detection rate as "the ability to detect the risk event with enough time to plan for a contingency and act upon the risk". Although this technique can be useful for project risk assessment and prioritization, it has some limitations. The major shortcoming of this technique is to assign a single value to the impact and probability of the risk event. Most of the time, it is very difficult to predict a single value for these variables. In addition, using a single value is not realistic as these values vary depending on different conditions. To overcome this limitation, probability distribution functions can be used rather than using single values for the factors. This can be achieved by developing a new model where FMEA and Monte Carlo Simulation techniques are integrated. The objective of this research is to explore whether an integrated FMEA and Monte Carlo Simulation approach can be used to perform risk assessment and prioritization of risks in PPP projects. The applicability of the proposed approach is investigated in the context of wind power PPP investments. In this study, a generic approach is presented for risk assessment and then it is applied to a real case.

\section{Proposed generic model}

The generic model proposed in this study for the risk assessment and prioritization of PPP projects involves the steps illustrated in Fig. 1. The first step in the proposed model is the identification of the risk events associated with a particular PPP by means of an extensive literature review, a careful examination of PPP project documents, and semistructure interviews with experts.

- The literature review includes all studies related to PPP projects and the identification of possible risk events in these projects.

- The examination of PPP project documents involves looking into frequently used contractual agreements between public agencies and private consortia, feasibility studies, and virtual models with the hope of identifying additional risk events to those identified in the literature review. 


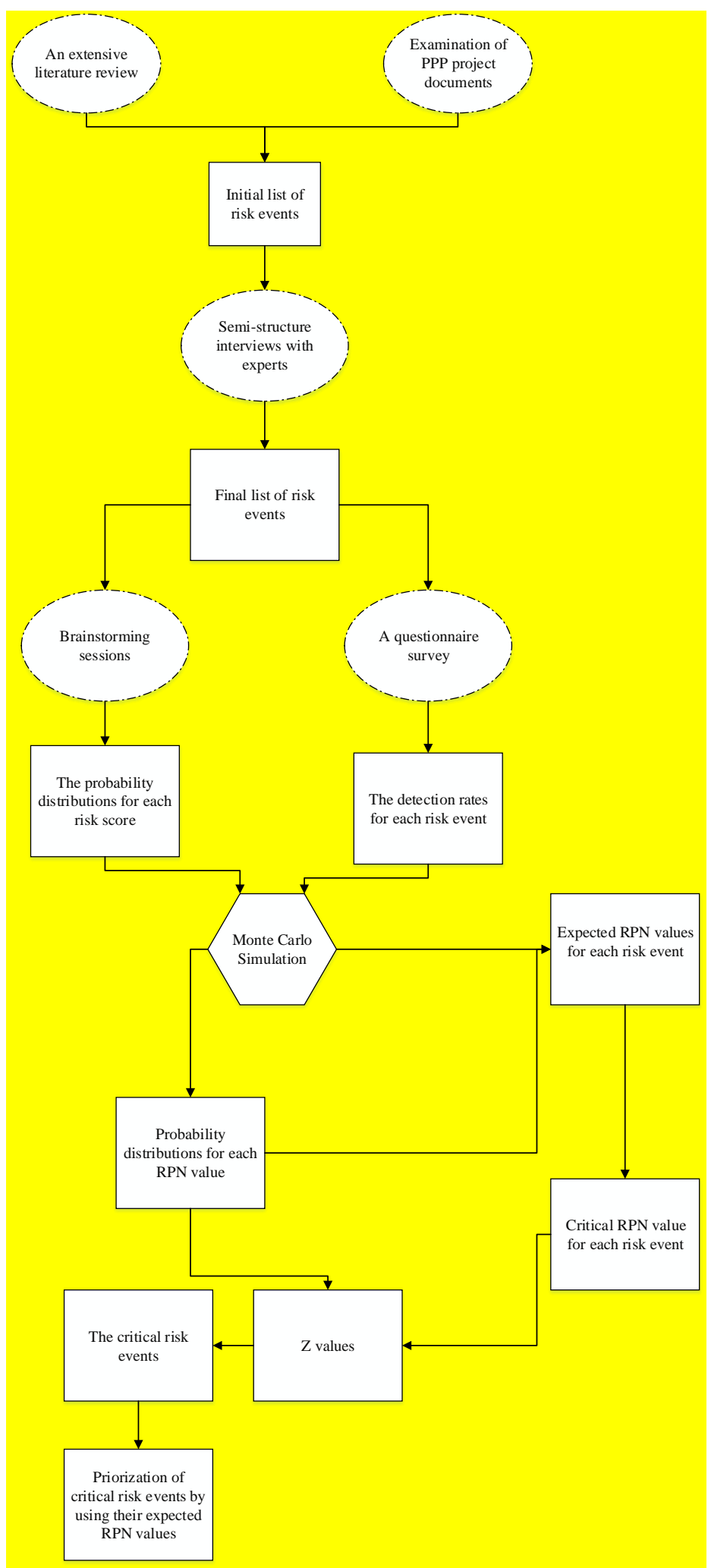

Fig. 1. The generic model for the risk assessment of PPP projects 
- To draw the final list of risk events, semistructured interviews are conducted with experts including both researchers and practitioners with direct involvement in PPP projects. The initial list of possible risk events, which was created after the literature review and the examination of PPP project documents is circulated to the interviewees with a request to check and finalize this list by adding or removing possible risk events. The selection criteria for researchers include (1) at least two publications related to risk assessment of PPP investments and (2) at least one research project related to PPP investments. The selection criteria for practitioners include (1) at least ten years of experience in PPP investments and (2) having been involved in at least two PPP projects.

The next step is to set up the probability distributions of the risk scores. The idea in the proposed model is to develop a probability distribution for each risk score rather than assigning determinate values to the impact of each risk event. FMEA identifies a Risk Priority Number (RPN) by multiplying impact (I), probability of occurrence (P), and detection rate (D) (Eq. 1).

$\mathrm{RPN}=\mathrm{I} \times \mathrm{P} \times \mathrm{D}$

The risk score $(\mathrm{R})$ is calculated for each risk event by multiplying the impact (I) and the probability (P) of a risk event (Eq. 2).

$\mathrm{R}=\mathrm{I} \times \mathrm{P}$

Therefore, RPN is found as the product of the risk score (R) and detection rate (D) (Eq. 3).

$\mathrm{RPN}=\mathrm{R} \times \mathrm{D}$

Brainstorming sessions are recommended with a representative sample of practitioners to extract information about the impact of the risk events on project performance and to estimate the probability distribution of each risk event. It should be noted that risk events impact several performance indicators (such as time, cost, and quality) of the project. Therefore, the performance criteria should be communicated to the participants before the brainstorming session, so that the probability distributions of risk scores are assigned accordingly.

As per Equation 3, there are two variables ( $R$ and D) that affect RPN. After setting up the probability distribution for each risk score (R), the detection rates for each risk event are identified by using a questionnaire survey administered to the same sample of experts who participated in the brainstorming sessions. To reduce the spread of the detection rates (D), the Delphi technique is to be used with at least two successive rounds. Ametepey et al. [39] define Delphi as a survey conducted in two or more rounds and affords the participants the latitude to modify their original assessments in successive rounds based on the average results of the preceding rounds. A high degree of consensus can be reached among experts when this technique is used.

Once the detection rates and the probability distribution of each risk score are determined, Monte Carlo Simulation is performed to calculate the RPN of each risk event. When a user enters the probability distributions for the risk events, Monte Carlo Simulation provides the user with a range of possible outcomes. Monte Carlo Simulation can be performed by using standalone software or an addin to Microsoft Excel. In this research, @RISK was chosen as it is widely used in practice.

Once RPN distributions are determined for the risk events by performing Monte Carlo simulation, the critical RPN value must be determined. It should be noted that there is no RPN value that can be universally considered critical, i.e., that can be used for all projects. The critical RPN is projectspecific, and depends on several factors such as project type, risk scores, RPN values. For example, the critical RPN can be determined by first calculating the expected value obtained from the RPN distribution of each risk event and then by considering the average of these expected values across all risk events (Eq. 4).

Critical RPN $=\frac{\sum_{\mathrm{i}=1}^{\mathrm{n}} \mathrm{E}_{\mathrm{i}}}{\mathrm{n}}$ 
where: $E_{i}$ is the expected value of the $i^{\text {th }}$ risk event, and $\mathrm{n}$ represents the total number if risk events in a particular PPP project.

The last step in the proposed model is the assessment and prioritization of risk events. This step involves a factor denoted by $\mathrm{Z}$ that shows the probability of a risk event's RPN being smaller or greater than the critical RPN. This factor $(\mathrm{Z})$ can actually be found for each risk event by calculating the area under the RPN probability distribution curve to the right of the critical RPN value.

$\mathrm{Z}_{\mathrm{i}}=\mathrm{P}_{\mathrm{i}}\left(\mathrm{RPN}_{\mathrm{i}}>\mathrm{RPN}_{\text {critical }}\right)$

where $Z_{i}$ is the probability of the $i^{\text {th }}$ risk event to have an RPN that is greater than the critical RPN.

The assessment of the risk events is carried out by comparing a risk event's RPN against the critical $\mathrm{RPN}$. If a risk event has a $\mathrm{Z}$ value greater than zero, this risk event is considered a critical risk event, otherwise it is a non-critical risk event. It should also be noted that the $\mathrm{Z}$ values of each risk event can also be found by using the Monte Carlo simulation software.

The prioritization of the critical risk events is performed by ranking them according to their expected RPN values. The risk event with a greater expected RPN is more critical than a risk event that has a smaller expected RPN. The generic model proposed here was used to assess and prioritize risk events in a real PPP wind power investment as described in detail in the following section.

\section{Case study}

The proposed model was applied to a real wind power investment located in the Aegean region of Turkey. The project was tendered on a PPP basis and had a 7 MW capacity.

As seen in Table 1, seventeen risk events were identified by performing a literature review of related studies, by examining the PPP agreement and all related documents, and by conducting semistructured interviews with 20 experts, the selection criteria of which was presented in the preceding section.
Table 1. Risk events for PPP wind power investments

\begin{tabular}{|c|c|}
\hline Risk Event & Description \\
\hline Risk Event 1 & Unfavorable wind speed \\
\hline Risk Event 2 & $\begin{array}{l}\text { Fluctuation in market } \\
\text { demand }\end{array}$ \\
\hline Risk Event 3 & Changes in tariff rates \\
\hline Risk Event 4 & Design deficiency \\
\hline Risk Event 5 & $\begin{array}{l}\text { Poor performance of } \\
\text { contractor }\end{array}$ \\
\hline Risk Event 6 & $\begin{array}{l}\text { Poor performance of } \\
\text { operator }\end{array}$ \\
\hline Risk Event 7 & Change in tax regulations \\
\hline Risk Event 8 & Interest rate volatility \\
\hline Risk Event 9 & Fluctuation in inflation rates \\
\hline Risk Event 10 & Fluctuation in exchange rates \\
\hline Risk Event 11 & $\begin{array}{l}\text { Unfavorable geotechnical } \\
\text { conditions }\end{array}$ \\
\hline Risk Event 12 & Unavailability of resources \\
\hline Risk Event 13 & Change in government \\
\hline Risk Event 14 & Public opposition to project \\
\hline Risk Event 15 & Delay in approval/permits \\
\hline Risk Event 16 & $\begin{array}{l}\text { Adverse impact of political } \\
\text { pressure }\end{array}$ \\
\hline Risk Event 17 & Changes in laws \\
\hline
\end{tabular}

Later a brainstorming session was organized with 12 experts in order to determine the probability distributions of the risk scores for each risk event. Choosing appropriate experts was important for realistic results; in addition to the selection criteria discussed in the preceding section, it was made sure that none of the experts were directly involved in the wind power generation project considered in the case study, hence minimizing possible prejudice or bias.

The participants of this brainstorming session were informed about the characteristics of the case study (such as total capacity, location, duration of operation period, etc.) and were given a list of the risk events associated with this project. For each risk score, the best, worst and expected values, and the probability distributions were assigned as a result of group discussion until they reached a consensus. A sample of risk events and their associated probability distributions used to calculate their risk scores are presented in Fig. 2. 

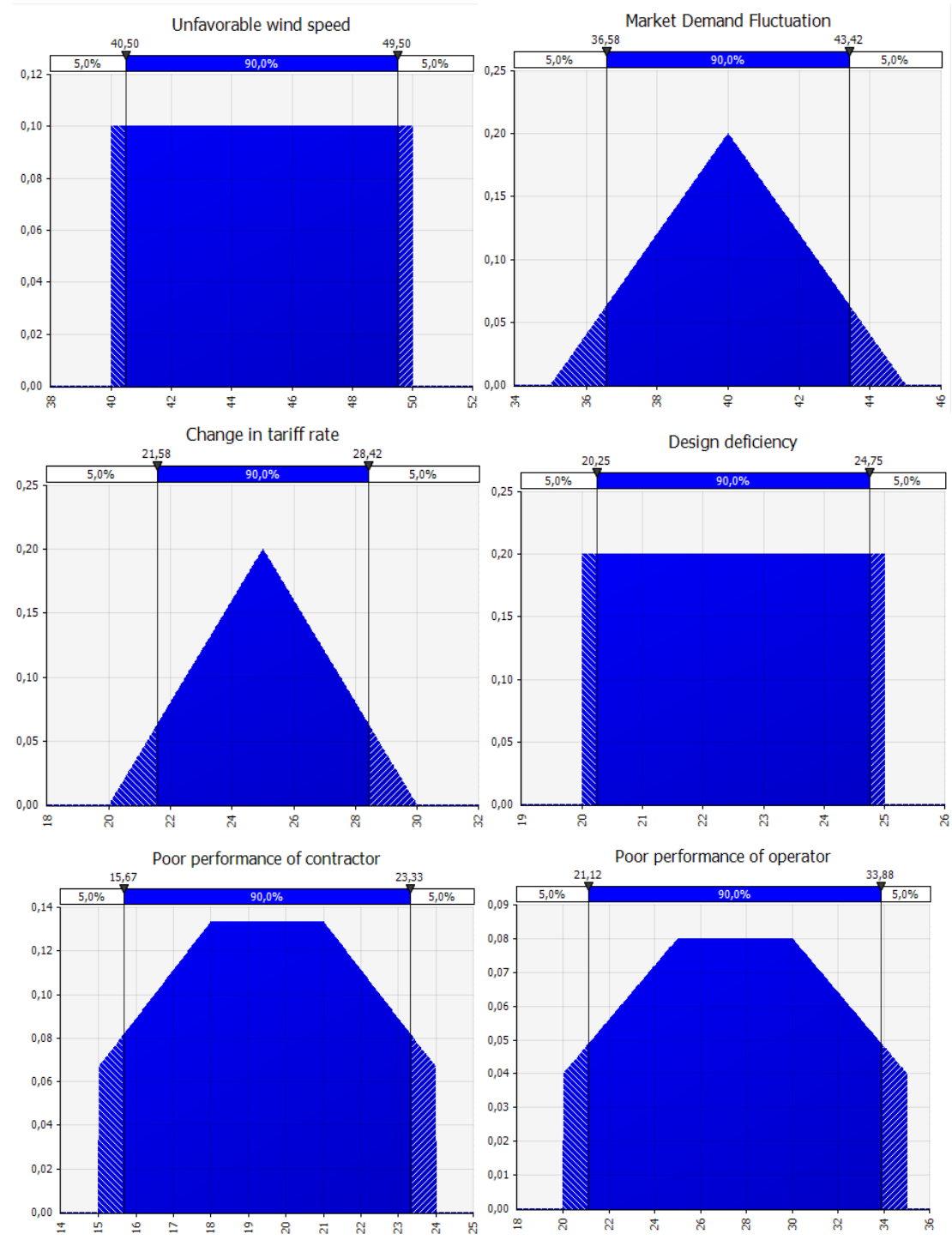

Fig. 2. Probability distributions of the risk scores of a sample of risk events

To determine the detection rate of each risk event, a questionnaire survey was administered to the same 20 experts who previously finalized the list of possible risk events. The respondents used a 10-point Likert scale, where "1" denotes that the risk event can be easily detected, and " 10 " denotes that it is impossible to detect this risk event. Two Delphi rounds were administered to elicit the detection rates of the risk events. After the second round, the mode of respondents' ratings was found acceptable as reasonable convergence was achieved. The detection rates are shown in Table 2.
After the probability distributions of risk scores and detection rates were entered to the simulation tool @RISK as an input variable, Monte Carlo simulation was performed to calculate the possible RPN values and to determine the probability distributions of RPN values for each risk event (Fig. 3). With the help of the RPN probability distributions, the expected RPN was found for each risk event (Table 3), and then the critical RPN was calculated as 217 by taking the average of all expected values using Eq. (4). 
Table 2. Detection Rates for the risk events

\begin{tabular}{lc}
\hline Risk event & Detection rate \\
\hline Unfavorable wind speed & 10 \\
Fluctuation in market demand & 8 \\
Changes in tariff rates & 5 \\
Design deficiency & 6 \\
Poor performance of contractor & 5 \\
Poor performance of operator & 9 \\
Change in tax regulations & 7 \\
Interest rate volatility & 7 \\
Fluctuation in inflation rates & 7 \\
Fluctuation in exchange rates & 3 \\
Unfavorable geotechnical conditions & 4 \\
Unavailable resources & 4 \\
Change in government & 8 \\
Public opposition to project & 2 \\
Delay in approval/permits & 4 \\
Adverse impact of political pressure & 4 \\
Changes in laws & 8 \\
\hline
\end{tabular}
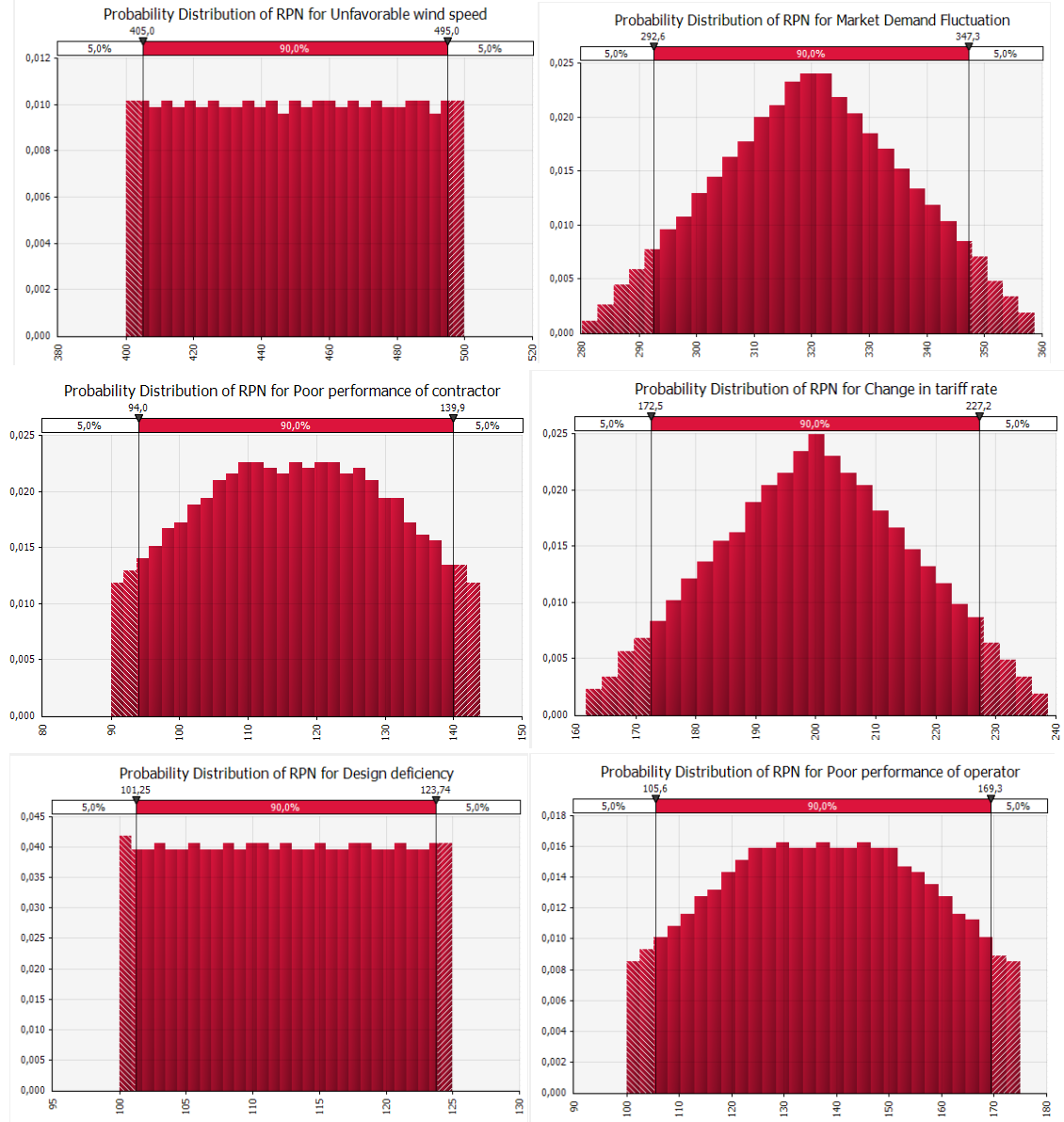

Fig. 3. Probability distributions of the RPN values of a sample of risk events 
Table 3. Expected RPN values for risk events

\begin{tabular}{lc}
\hline Risk event & Expected RPN value \\
\hline Unfavorable wind speed & 450.0 \\
$\begin{array}{l}\text { Fluctuation in market } \\
\text { demand }\end{array}$ & 320.0 \\
Changes in tariff rates & 200.0 \\
Design deficiency & 112.5 \\
Poor performance of & 117.0 \\
contractor & \\
Poor performance of & 137.5 \\
operator & 292.5 \\
Change in tax regulations & 385.0 \\
Interest rate volatility & 350.0 \\
Fluctuation in inflation rates & 420.0 \\
Fluctuation in exchange rates & 22.5 \\
Unfavorable geotechnical & 180.0 \\
conditions & 360.0 \\
Unavailable resources & \\
Change in government & 50.0 \\
Public opposition to project & 141.3 \\
Delay in approval/permits & 62.0 \\
$\begin{array}{l}\text { Adverse impact of political } \\
\text { pressure }\end{array}$ & \\
Changes in laws & \\
\hline & \\
\hline
\end{tabular}

This calculation was repeated for all risk events, and the $\mathrm{Z}$ values for all risk events were tabulated (Table 4). The risk events with a $Z$ value greater than zero were critical risk events and are shown in italics in Table 4. The prioritization of the critical risk events was performed by ranking their expected RPNs from highest to lowest, as shown in Table 5.

\section{Discussion of results}

According to Table 5, the most significant risk event in the case considered in this study is "unfavorable wind speed". Although the Turkish Government requires that the private consortium measure the wind speed by setting up an anemometer at the planned location of the investment at least one year before the start of the agreement [40], most of the time, the actual wind speeds do not match a one-year record of measurements.
Table 4. $\mathrm{Z}$ values for each risk event

\begin{tabular}{lc}
\hline Risk Event & Z value \\
\hline Unfavorable wind speed & 1 \\
Fluctuation in market demand & 1 \\
Changes in tariff rates & 0.17 \\
Design deficiency & 0 \\
Poor performance of contractor & 0 \\
Poor performance of operator & 0 \\
Change in tax regulations & 1 \\
Interest rate volatility & 1 \\
Fluctuation in inflation rates & 1 \\
Fluctuation in exchange rates & 1 \\
Unfavorable geotechnical conditions & 0 \\
Unavailable resources & 0 \\
Change in government & 0 \\
Public opposition to project & 0 \\
Delay in approval/permits & 0 \\
Adverse impact of political pressure & 0 \\
\hline Changes in laws & 0 \\
\hline
\end{tabular}

Table 5. Prioritization of critical risk events

\begin{tabular}{lc}
\hline Critical Risk Event & Expected RPN Value \\
\hline Unfavorable wind speed & 450 \\
Fluctuation in exchange rates & 420 \\
Interest rate volatility & 385 \\
Changes in laws & 360 \\
Fluctuation in inflation rates & 350 \\
Fluctuation in market & \\
demand & 320 \\
Changes in tax regulations & 293 \\
Changes in tariff rates & 200 \\
\hline
\end{tabular}

Indeed, it is very difficult, almost impossible, to forecast wind speeds, and their large fluctuations. In addition to its undetectability, wind speed has a major effect on the amount of energy produced, and as a result, on the revenue generated by the investment. As this risk event is uncontrollable risk event, the aim of the risk response strategy is to minimize severity of this risk event. For this 
purpose, the period for record of measurements can be increased. When the measurement period increases, the accuracy of wind speed estimation also increases.

The second most significant risk event is "fluctuations in exchange rates". The substantial portion of the equipment and materials used in wind power investments are imported, and consequently their costs are directly affected by fluctuations in exchange rates [41]. As a result, fluctuations in exchange rates directly affect the profitability of the investment. It is worth noting that this risk event depends largely on the economic conditions in the country [42].

The third most significant risk event is "interest rate volatility". Interest rate volatility has major effects on the rate of return and the potential profit generated by the project [43]. Since most wind power generation investments are performed by using bank credits, there is a strong correlation between the interest rate and total project cost. Similar to fluctuation in exchange rates, volatility in interest rates depends on the economic conditions of the country. It is reasonable to assume that if the proposed model had been applied to a case study in a more developed country with a more stable economy, "fluctuation in exchange rates" and "interest rate volatility" would not have ranked at the top of the list of critical risk events as they were in Turkey. To mitigate these risk events, different financial techniques can be used. For instance, "fluctuation in exchange rates" can be allocated using matching principle.

The least significant risk event is "unfavorable geotechnical conditions". As the wind speed is measured by setting up an anemometer at the planned location of the investment, the geological condition of the location is not difficult to explore. As a result, the detection rate of this risk event is smaller compared to the other risk events.

As stated earlier, one of the most important shortcomings of traditional FMEA is to assign a single value to each variable in RPN calculations. To address this drawback, a great deal of effort has been given. Most of the studies have proposed new models to overcome this challenge combining
FMEA and fuzzy logic [33, 35]. As possibilistic approach is used for each variable in fuzzy logic, it doesn't take into account the numerical compensation between the impact and the probability of a risk event [44]. However, in the proposed approach, instead of determining the the impact and the probability of a risk event separately, probability distributions were assigned for the risk score of each risk event.

A meeting was arranged with the 20 experts who participated in the interviews and brainstorming sessions to discuss the performance of the proposed model in the case study. The participants were asked their opinions about the results. They found the ranking of the risk events reasonable. They pointed out that the detection rate is an important factor in ranking the criticalness of risk events and they supported the fact that the proposed model does indeed consider the detection rate prominently in prioritizing the risk events. To highlight this issue, they stated that if the risk events had been prioritized by using only their expected risk scores, "unfavorable wind speed" would not have been the most significant risk event, whereas based on their experiences, they were unanimous in their opinion that "unfavorable wind speed" is the most critical risk event in PPP wind power generation investments. In addition, they stated that the proposed model which includes probabilistic assessments of the risk scores, is more realistic compared to the traditional FMEA method that uses deterministic values.

\section{Conclusions}

This paper presents an integrated FMEA and Monte Carlo Simulation model that can be used to assess the risk events that affect PPP wind power generation investments. One should be able to identify and prioritize the critical risk events before entering into such an agreement. This can be done by using the proposed model. First, the initial list of risk events is identified by performing an extensive literature review, by examining frequently used PPP documents, and by conducting semi-structured interviews with experts to finalize this list. Second, a brainstorming session is 
arranged to determine the probability distribution of each risk score. Third, a questionnaire survey is administered to experts to rate the detection rate of each risk event. Fourth, Monte Carlo simulation is performed to identify the probability distributions of RPN values and to calculate the expected RPN for each risk event. Fifth, the probability factor $Z$ of each risk event is calculated by using the event's probability distribution and expected RPN. Sixth, risk events are assessed, and critical risk events are identified by using these $\mathrm{Z}$ values. Finally, the critical risk events are prioritized according to their expected RPN.

To demonstrate the applicability of the model, a real PPP wind power generation project undertaken in Turkey was used as a case study. The risk rankings presented in Table 4 show that "changes in laws", "unfavorable wind speed", "fluctuation in inflation rates", "fluctuation in exchange rates", "fluctuation in market demand", "interest rate volatility", "changes in tax regulations", and "changes in tariff rates" are critical risk events. Furthermore, the top three important risk events are "unfavorable wind speed", "fluctuation in exchange rates", and "interest rate volatility". The proposed model sheds light on the risk assessment process and may be conducive to successful projects.

The practical and theoretical contributions of this study include:

- The proposed model helps public agencies and private consortia to identify the risk events in PPP projects.

- The proposed model can guide public agencies and private consortia in risk assessment and prioritization of risk events in PPP projects.

- The proposed model is the first study in the literature that integrates FMEA and Monte Carlo simulation to perform risk assessment in PPP projects.

It is worth noting that the proposed model can be used for other types of PPP projects by adjusting the risk events and by duplicating the steps used in the development of the proposed model.

It should be noted that the subjectivity involved in setting up the probability distributions for the risk scores and estimating the detection rates of the risk events is a limitation of the proposed model. Future studies can be conducted to reduce the subjectivity of these variables. In addition, it is possible to experiment with alternative methodologies in future work to determine the critical value of RPN.

\section{Declaration of conflicting interests}

The author(s) declared no potential conflicts of interest with respect to the research, authorship, and/or publication of this article.

\section{References}

[1] Project Management Institute (2013) A guide to the project management body of knowledge (PMBOK ${ }^{\circledR}$ guide), fifth edition, Newtown Square, PA: Project Management Institute.

[2] Gao J, Ren H, Cai W (2019) Risk assessment of construction projects in China under traditional and industrial production modes. Engineering, Construction and Architectural Management, 26(9):2147-2168.

[3] Srinivas K (2019) Process of Risk Management, Perspectives on Risk, Assessment and Management Paradigms, Ali G. Hessami, IntechOpen. DOI: 10.5772/intechopen.80804. Available from: https://www.intechopen.com/books/perspectiveson-risk-assessment-and-managementparadigms/process-of-risk-management

[4] Dikmen I, Birgonul MT, Ozorhon B (2007) Project appraisal and selection using the analytic network process. Canadian Journal of Civil Engineering 34(7):786-792.

[5] Ahmadabadi AA, Heravi G (2019) The effect of critical success factors on project success in publicprivate partnership projects: a case study of highway projects in Iran. Transport Policy 73:152161.

[6] Liu J, Love PED, Smith J, Regan M, Davis PR (2015) Life cycle critical success factors for public-private partnership infrastructure projects. Journal of Management in Engineering 31(5): 04014073.

[7] SRA (2015) SRA glossary. http://www.sra.org/sites/default/files/pdf/SRA_glo ssary_20150622.pdf.

[8] Siu M-FF, Leung W-YJ, Chan W-MD (2018) A data-driven approach to identify-quantify-analyse construction risk for Hong Kong NEC projects. 
Journal of Civil Engineering and Management, 24(8):592-606.

[9] Mansouri M, Nilchiani R, Mostashari A (2009) A risk management-based decision analysis framework for resilience in maritime infrastructure and transportation systems. 2009 IEEE International Systems Conference Proceedings, art. no. 4815768 , pp. $35-41$.

[10] Dey PK (2012) Project risk management using multiple criteria decision-making technique and decision tree analysis: A case study of Indian oil refinery. Production Planning and Control, 23(12): 903-921.

[11] Li Y, Wang X (2019) Using fuzzy analytic network process and ism methods for risk assessment of public-private partnership: A china perspective. Journal of Civil Engineering and Management, 25(2):168-183.

[12] Bu-Qammaz AS, Dikmen I, Birgonul MT (2009) Risk assessment of international construction projects using the analytic network process. Canadian Journal of Civil Engineering 36(7):11701181.

[13] Wu Y, Li L, Xu R, Chen K, Hu Y (2017) Risk assessment in straw-based power generation public-private partnership projects in China: A fuzzy synthetic evaluation analysis. Journal of Cleaner Production, 161:977-990.

[14] Valipour A, Yahaya N, Md Noor N, Kildienė S, Sarvari H, Mardani A (2015) A fuzzy analytic network process method for risk prioritization in freeway PPP projects: an Iranian case study. Journal of Civil Engineering and Management, 21(7):933-947.

[15] Do ST, Likhitruangsilp V, Kiet TT, Nguyen PT (2017) Risk assessment for international construction joint ventures in Vietnam. International Journal of Advanced and Applied Sciences 4(6):104-114.

[16] Wang D, Li K, Fang S (2018) Analyzing the factors influencing trust in a construction project: Evidence from a Sino-German eco-park in China. Journal of Civil Engineering and Management, 24(4):331-343.

[17] Dehdast G, Zin RM, Ferwati MS, Abdullahi MM, Keyvanfar A, McCaffer R (2017) DEMATELANP Risk Assessment in Oil and Gas Construction Projects. Sustainability, 9(1420).

[18] Comu S, Elibol AY, Yucel B (2021) A risk assessment model of commercial real estate development projects in developing countries.
Journal of Construction Engineering, Management \& Innovation, 4(1):052-067.

[19] Liu X, Fang J (2019) Risk Identification and Evaluation of Urban Underground Pipe Gallery PPP Project Based on Improved AHP. ICCREM 2019: Innovative Construction Project Management and Construction Industrialization Proceedings of the International Conference on Construction and Real Estate Management, pp. 415-424.

[20] Li J, Zou PXW (2011) Fuzzy AHP-based risk assessment methodology for PPP projects. Journal of Construction Engineering and Management. 137(12):1205-1209.

[21] Li Y, Wang X (2018) Risk assessment for publicprivate partnership projects: using a fuzzy analytic hierarchical process method and expert opinion in China. Journal of Risk Research, 21(8):952-973.

[22] Jokar E, Aminnejad B, Lorak A (2020) Risk prioritization and selectionof contractor participating in Public-Private Partnership (PPP) infrastructure project using Hybrid Fuzzy AHP and Fuzzy TOPSIS (Case Study: Saveh-Salafchegan Freeway Project). Journal of Construction Engineering, Management \& Innovation, 3(1):116.

[23] Sarvari H, Valipuor A, Yahaya N, Norhazilan MN (2014) Risk ranking of Malaysian public private partnership projects. Applied Mechanics and Materials, 567:613-618.

[24] Almarri K, Alzahrani S, Boussabaine H (2019) An evaluation of the impact of risk cost on risk allocation in public private partnership projects. Engineering, Construction and Architectural Management, 26(8):1696-1711.

[25] Nguyen D, Garvin M (2016) Risk Allocation and Management Practices in Highway PPP Contracts: Pilot Study of Virginia. Construction Research Congress 2016: Old and New Construction Technologies Converge in Historic San Juan Proceedings of the 2016 Construction Research Congress, CRC 2016, pp. 559-568.

[26] Kumar L, Jindal A, Velaga NR (2018) Financial Risk Assessment and Modelling of PPP Based Indian Highway Infrastructure Projects. Transport Policy 62:2-11.

[27] Wibowo A, Permana A, Kochendörfer B, Kiong RTL, Jacob D, Neunzehn D (2012) Modeling Contingent Liabilities Arising from Government Guarantees in Indonesian BOT/PPP Toll Roads. 
Journal of Construction Engineering and Management, 138(12):1403-1410.

[28] Carbonara N, Costantino N, Pellegrino R (2014) Concession period for PPPs: A win-win model for a fair risk sharing. International Journal of Project Management, 32(7):1223-1232.

[29] Jin H, Liu S, Liu C, Udawatta N (2019) Optimizing the concession period of PPP projects for fair allocation of financial risk. Engineering, Construction and Architectural Management, 26(10):2347-2363.

[30] Liu Q, Liao Z, Guo Q, Degefu DM, Wang S, Jian F (2019) Effects of short-term uncertainties on the revenue estimation of PPP sewage treatment projects. Water (Switzerland), 11(6),1203.

[31] Wang X, Shi L, Wang B, Kan M (2019) A method to evaluate credit risk for banks under PPP project finance. Engineering, Construction and Architectural Management, 27(2):483-501.

[32] Dikmen I, Birgonul MT, Han S (2007) Using fuzzy risk assessment to rate cost overrun risk in international construction projects. International Journal of Project Management, 25(5):494-505.

[33] Abdelgawad M, Fayek AR (2010) Risk management in the construction industry using combined fuzzy FMEA and fuzzy AHP. Journal of Construction Engineering and Management, 136(9):1028-1036.

[34] Carbone TD, Tippett DD (2004) Project risk management using the project risk FMEA. Engineering Management Journal. 14(4):28-35.

[35] Ahmadi M, Behzadian K, Ardeshir A, Kapelan Z (2017) Comprehensive risk management using fuzzy FMEA and MCDA techniques in highway construction projects. Journal of Civil Engineering and Management, 23(2):300-310.

[36] Mecca S, Masera M (1999) Technical risk analysis in construction by means of FMEA methodology. In: Hughes, W (Ed.), 15th Annual ARCOM Conference, 15-17 September 1999, Liverpool John Moores University. Association of
Researchers in Construction Management, Vol. 2, 425-34.

[37] Dabbagh R, Yousefi S (2019) A hybrid decisionmaking approach based on FCM and MOORA for occupational health and safety risk analysis. Journal of Safety Research, 71:111-123.

[38] Park K, Lee HW, Choi K, Lee S-H (2019) Project Risk Factors Facing Construction Management Firms. International Journal of Civil Engineering, 17(3):305-321.

[39] Ametepey SO, Aigbavboa C, Thwala WD (2019) Assessment of the Use of Delphi Technique in Sustainable Infrastructure Development Research. Creative Construction Conference 2019, 29 June2 July 2019, Budapest, Hungary. https://doi.org/10.3311/CCC2019-089

[40] The Official Gazette of The Republic of Turkey (2013),

https://www.resmigazete.gov.tr/eskiler/2013/03/20 130327-13.htm, accessed December 10, 2020.

[41] Osei-Kyei R, Chan APC (2017) Implementation constraints in public-private partnership: Empirical comparison between developing and developed economies/countries. Journal of Facilities Management, 15(1):90-106.

[42] Ameyaw EE, Chan APC (2015) Evaluation and ranking of risk factors in public-private partnership water supply projects in developing countries using fuzzy synthetic evaluation approach. Expert Syst. Appl. 42 (12):5102-5116.

[43] Sy DT, Likhitruangsilp V, Onishi M, Nguyen PT (2017) Impacts of risk factors on the performance of public-private partnership transportation projects in Vietnam. ASEAN Engineering Journal, $7(2): 30-52$.

[44] Zhang Z, Chu X (2011) Risk prioritization in failure mode and effects analysis under uncertainty. Expert System with Application 38:206-214. 